$\underline{\xi}=-m$

\title{
Protective effects of prebiotic (resistant maltodextrin) and silymarin against toxicity of carbon tetrachloride in liver rat and kidney
}

\author{
M. G. A. EL. SAYED ${ }^{1 *}$, ENAS. A. H. FARAG ${ }^{2}$, HEBA. M. Nasr ${ }^{3}$ \\ ${ }^{1}$ Department of pharmacology, faculty of veterinary medicine Benha university Egypt \\ ${ }^{2}$ Professor of pharmacology at Animal health research institute Benha branch Egypt \\ ${ }^{3}$ Pharmacist at Hospital of Benha university, faculty of medicine Benha university Egypt
}

*Corresponding author E-mail:

\begin{abstract}
Exposure to carbon tetrachloride induces acute and chronic hepatic injuries as well as renal injuries in rats. Therefore, the current study aimed to evaluate the protective role of prebiotic (digestion resistant maltodextrin) and silymarin against carbon tetrachloride -induced heptorenal toxicity in albino rats. Six groups with ten rats each were used for this purpose; these groups included the control vehicle group that received saline daily for 30 days, prebiotic group ( $1 \mathrm{~g} / \mathrm{kg}$, orally) daily for 30 days; silymarin group (200 mg/kg orally) daily for 30 days; carbon tetrachloride group $(2.5 \mathrm{ml} / \mathrm{kg}$ intraperitoneally twice per week for three week; the prebiotic - carbon tetrachloride group; the silymarin - carbon tetrachloride group. The results revealed that carbon tetrachloride significantly increased serum levels of alanine aminotransferase, aspartate aminotransferase, alkaline phosphatase, total bilirubin cholesterol, triglyceride, urea and creatinine. In addition, there were substantial increase in lipid peroxidation (malondialdehyde) and level of glucose with significant decreases in albumin, total protein, creatinine kinase, hemoglobin and red blood cells. Carbon tetrachloride also caused histological changes in liver and kidney tissues. However, administration of prebiotic and silymarin alone ameliorated the carbon tetrachloride induced liver and kidney damage with improved hematological, lipid profile and glucose level.
\end{abstract}

Keywords: Use about five key words or phrases in alphabetical order, Separated by Semicolon.

\section{Introduction}

Prebiotics has illustrated as a novel concept in nutrition (Gibson and Roberfroid 1995), by semantic analogy with the term 'probiotics'. Prebiotics always refer to the fact that food ingredients or nutrients escape the digestion in the upper part of the digestive tract, are selectively fermented by bacteria, thereby changing the composition and/or activity of the gastrointestinal microbiota. An important point of the definition is that it must confer benefits upon host health (Roberfroid, 2007; Delzenne and Reid 2009). Prebiotics are non-digestible carbohydrates (Siti and Sarbini 2015). Resistant starch is defined as the sum of starch and the product of starch digestion that resists digestion in the small intestine of a normal human being (Englyst et al., 1992). The classified a soluble polysaccharide called 'retrograded resistant maltodextrins' as type three of resistant starch is by (Storey et al., 2007). Resistant maltodextrin is non-viscous dietary fiber made from corn starch by heat and enzymatic treatments followed by purification and spray drying (Takeiti et al., 2010) and fermented by intestinal bacterial flora, including bifidobacteria, resulting in an increase in the types and number of bacteria in the intestinal flora (Oku and Nakamura 2014). Resistant maltodextrin has inhibitory effect on the elevation of postprandial serum triglyceride (Kishimoto et al., 2009).Resistant maltodextrin may improve the risk factors of metabolic syndrome by reducing visceral fat and improving glucose and lipid metabolism (Hashizume et al., 2012).

Silymarin is a complex of flavonoid extracted from Silybum marianum seeds and has a potent hepatoprotective and antioxidant properties. The main isomeric flavonoids of Silymarin are silydianin, silychristine, silybin and isosilibinin (Comelli et al., 2007). Silybin is the major and most active component and represents about 60-70 \% of silymarin, followed by silychristin (20\%), silydianin (10\%), and isosilybin $(5 \%)$. It is widely used for the treatment of different symptoms including jaundice, hepatitis and diabetic nephropathy cirrhosis and may also have protective role against nephropathic processes (Kren and Walterova 2005) because of its anti-oxidant and membrane stabilizing properties. The anti-hepatotoxic mechanism of silymarin is associated with its stabilizing effect on cytoplasmic membranes Hahn et al., (1968) and enhancing hepatocyte protein synthesis (Takahara et al., 1986).

Carbon tetrachloride is a toxic substance and commonly used as a chemical intermediate, degreasing agent and dry cleaning fluid. Carbon tetrachloride induced massive damage to liver tissue as fatty degeneration, fibrosis and impairment of liver function (Matsubara et al., 1983). The mechanism of carbon tetrachloride injury involves oxidative damage by generation of reactive oxygen species (ROS) from biotransformation of carbon tetrachloride to trichloromethyl radicals (CCL3) Sheweita et al., 2001 . Carbon tetrachloride induced free radicals which are essential mediators of its nephrotoxic effects by lipid peroxidation and accumulation of dysfunction proteins (Khan et al., 2009). 


\section{Materials and methods}

\subsection{Drugs}

Prebiotic was marketed by pharmaceutical company, Mc Cord Research as Pinnaclife ${ }^{\circledR}$. International Free Trade, Cairo, Egypt .Silymarin obtained from medical union pharma pharmaceutical company as Hepaticum ${ }^{\circledR}$.Carbon tetrachloride obtained from the laboratory of toxicology faculty of veterinary, medicine Benha university, Pharmaceuticals industries (Cairo, Egypt). Total bilirubin, serum transaminases activities (AST and ALT), alkaline phosphatase (ALP), total protein, albumin, blood creatinine, blood urea, creatinine kinase, blood cholesterol, blood triglyceride, L-malondialdehyde (MDA), blood glucose, erythrocytic count (RBCs) and hemoglobin concentration (Hb) were kits were purchased from Diamond Company (Cairo, Egypt).

\subsection{Animals and experimental design}

60 male Wister albino rats weighting 200-280 g (age of rat 50 60 days) were obtained from animal house of Faculty of Veterinary Medicine, Benha University ,Egypt.The animals were housed in 49x35 cm stainless steel wire mesh cages with bedding of ground wood chips at $21 \mathrm{c}$. They were fed fresh-pelleted food and their water as placed in glass bottles of $500 \mathrm{ml}$. Rats were kept at a constant environmental and nutritional condition throughout the period of experiment. The animals were left for 15 days for acclimatization before the beginning of the experiment. The rats were randomly divided into main 6 groups. Group (1): Ten rats were administrated saline only $0.2 \mathrm{ml}$ daily for 30 days. Group (2): Ten rats were administrated prebiotic (digestion resistant maltodextrin) orally $1 \mathrm{~g} / \mathrm{kg}$ b.wt daily for 30 days. Group (3): Ten rats were administrated silymarin orally $200 \mathrm{mg} / \mathrm{kg} \mathrm{b}$.wt daily for 30 days. Group (4): Ten rats were administrated carbon tetrachloride $25 \%$ (dissolve in olive oil) intraperitoneally injection $2.5 \mathrm{ml} / \mathrm{kg}$ b.wt twice per week for three week to induce hepatic and renal toxicity. Group (5): Ten rats were administrated prebiotic (digestion resistant maltodextrin) as group 2 followed by carbon tetrachloride intraperitoneally injection $2.5 \mathrm{ml} / \mathrm{kg}$ b.wt twice per week for three week to induce hepatic and renal toxicity. Group (6): Ten rats were administrated silymarin as group 3 followed by carbon tetrachloride orally $2.5 \mathrm{ml} / \mathrm{kg} \mathrm{b}$.wt twice per week for three week to induce hepatic and renal toxicity.

\subsection{Blood collection}

Blood samples were taken at first, seventh and fourteenth day post-treatment in all groups after the end of administration .Two blood samples were taken from each rat in the group for both biochemical and hematological studies from median canthus of the eye. The first blood sample was collected without anticoagulant for separation of clear serum for biochemical analysis. The second sample of blood was collected in the test tube mixed with sodium Citrate $3.8 \%$ as anticoagulant, the sample was shake several times to ensure mixing of blood with anticoagulant. These blood samples were used for hematological studies to determine erythrocytic count and hemoglobin concentration.

\subsection{Serum biochemical analyses}

The collected sera were used for biochemical analysis to determine serum total bilirubin, serum transaminases activities (AST and ALT), alkaline phosphatase (ALP), total protein, albumin, blood creatinine, blood urea, creatinine kinase, blood cholesterol, blood triglyceride, L-malondialdehyde (MDA) and blood glucose

\subsection{Haematological studies}

The blood was collected with anticoagulant. These blood samples were used for hematological studies to determine erythrocytic count (RBCs) and hemoglobin concentration (Hb).

\subsection{Histopathology}

The treated rats were sacrificed at first day, seventh day and fourteenth day. Specimens were collected from liver and kidney from each sacrificed tested rats and fixed directly in formalin $10 \%$ for at least $24 \mathrm{~h}$, then the sample were washed under running tap water followed by immersion in serial dilutions of ethyl alcohol. Specimens were cleared in xylene and embedded in paraffin at 56 degree in hot air oven for twenty four hour. Paraffin bees wax tissue block were prepared for sectioning at 4 microns thickness by slidge microtome .The obtained tissue sections were collected on glass slides, deparaffinized and stained by hematoxylin and eosin stain for routine examination through the light microscope (Banchroft., et al 1996).

\subsection{Statistical analysis}

Statistical analysis was conducted with the Statistical Package for Social Science (SPSS Inc. Released, 2009) to determine if variables differed between groups, according to Snedecor and Cochran (1989). The Shapiro-Willk test was used to test the normal distribution of the data before statistical analysis was performed. Compare between means were conducted by one-way ANOVA and subsequent Duncan's multiple range test (Duncan, 1955). Probability values of less than 5\% $(\mathrm{P} \leq 0.05)$ were considered significant.

\section{Results}

Effect of prebiotic ( $1 \mathrm{~g} / \mathrm{kg}$ body weight) orally for 30 days , silymarin (SLY) at dose $200 \mathrm{mg} / \mathrm{kg}$ body weight orally for 30 days and carbon tetrachloride (CCL4) at dose $2.5 \mathrm{ml} / \mathrm{kg}$ body weight twice per week intraperitoneally for three week on serum total bilirubin, aspartate aminotransferase level(AST), alanine aminotransferase level(ALT) alkaline phosphatase (ALP), total protein, albumin, blood creatinine, blood urea, creatinine kinase, blood cholesterol, blood triglyceride, L-malondialdehyde (MDA) ,blood glucose , erythrocytic count(RBCs) and haemoglobin $(\mathrm{Hb})$. Values with different litters within different row differed significantly at $(\mathrm{P} \leq 0.05)$. 


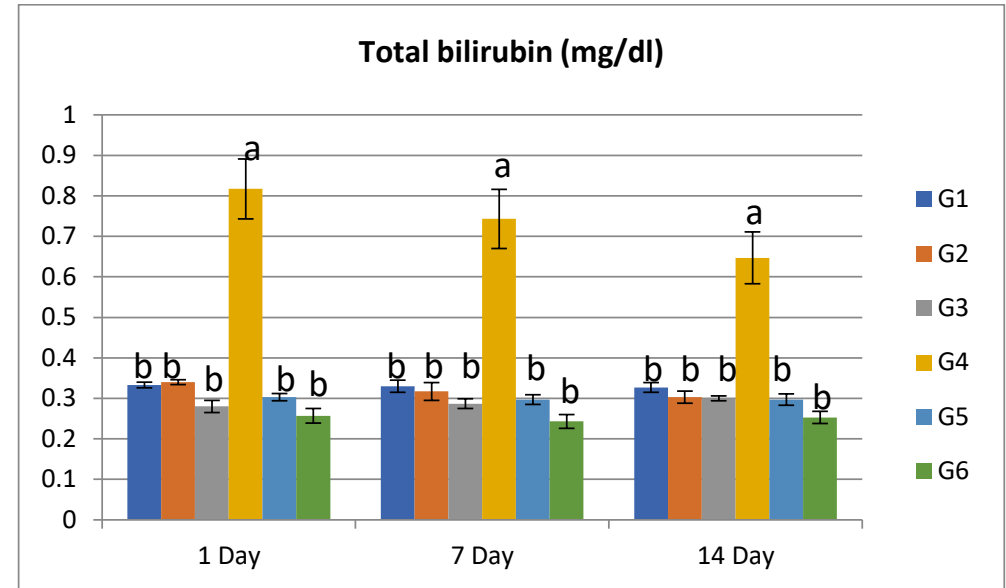

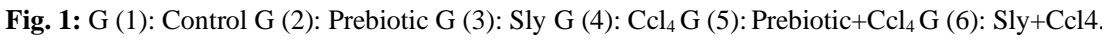

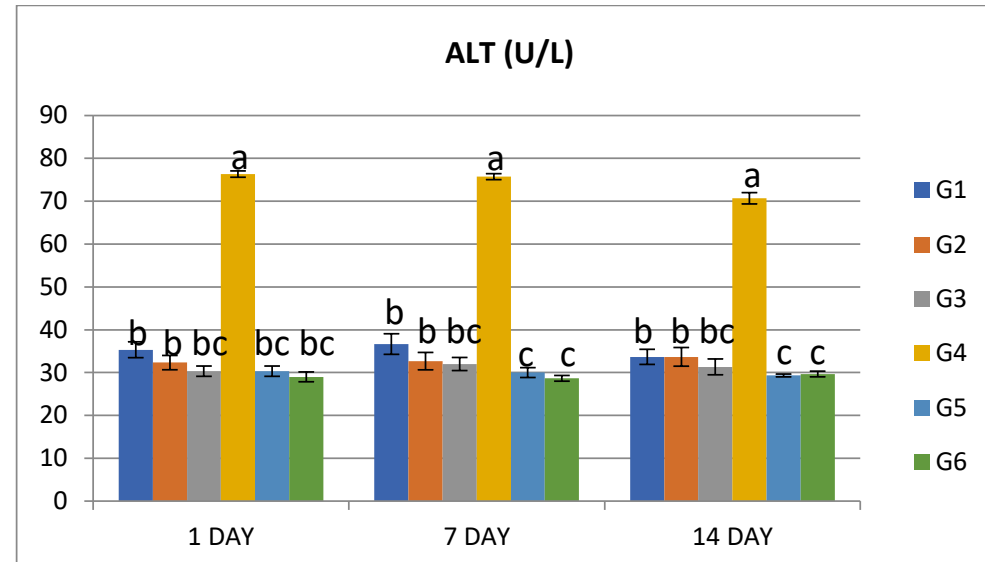

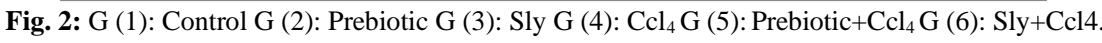

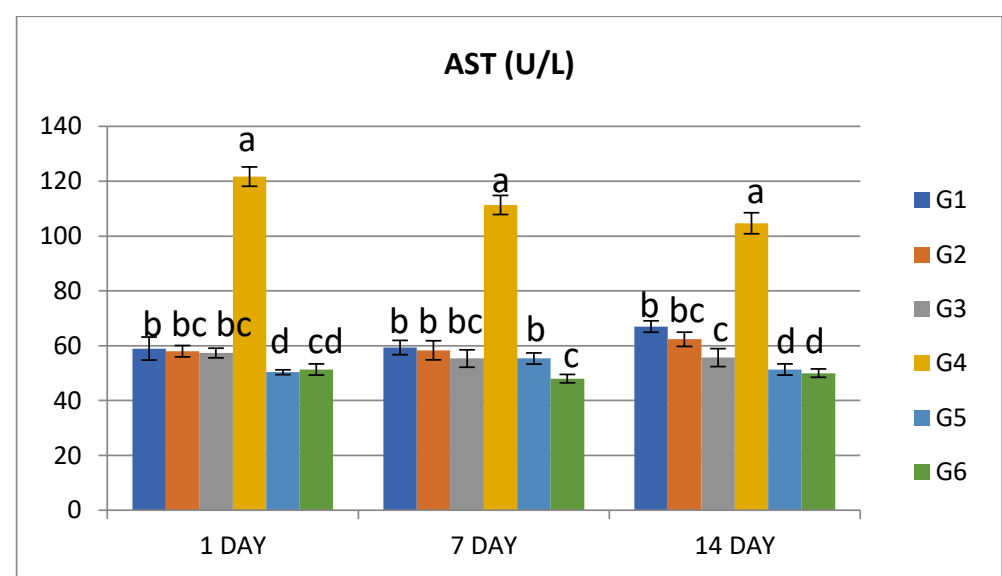

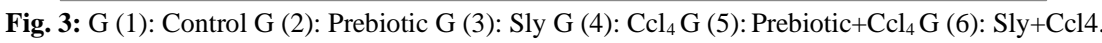

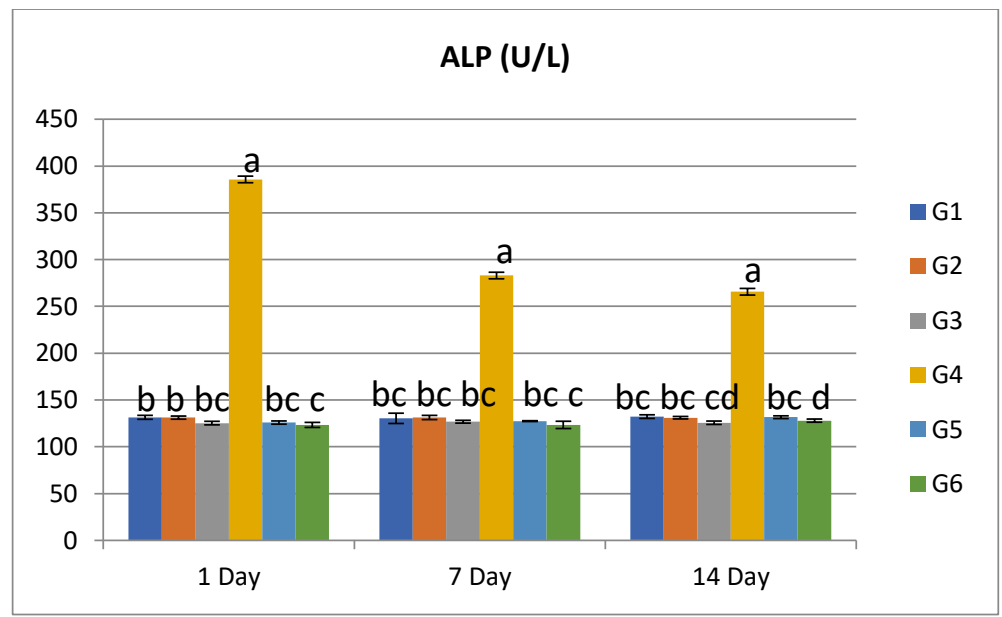


Fig. 4: G (1): Control G (2): Prebiotic G (3): Sly G (4): $\mathrm{Ccl}_{4} \mathrm{G}$ (5): Prebiotic+Ccl $_{4} \mathrm{G}$ (6): $\mathrm{Sly}+\mathrm{Ccl} 4$.

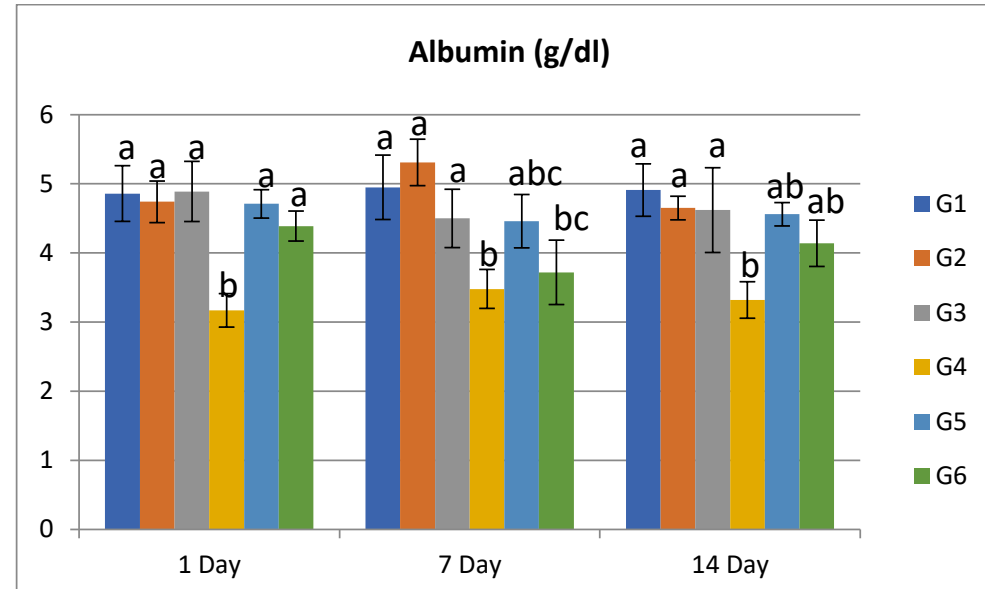

Fig. 5: G (1): Control G (2): Prebiotic G (3): Sly G (4): $\mathrm{Ccl}_{4} \mathrm{G}$ (5): Prebiotic+Ccl $_{4} \mathrm{G}$ (6): $\mathrm{Sly}+\mathrm{Ccl} 4$.

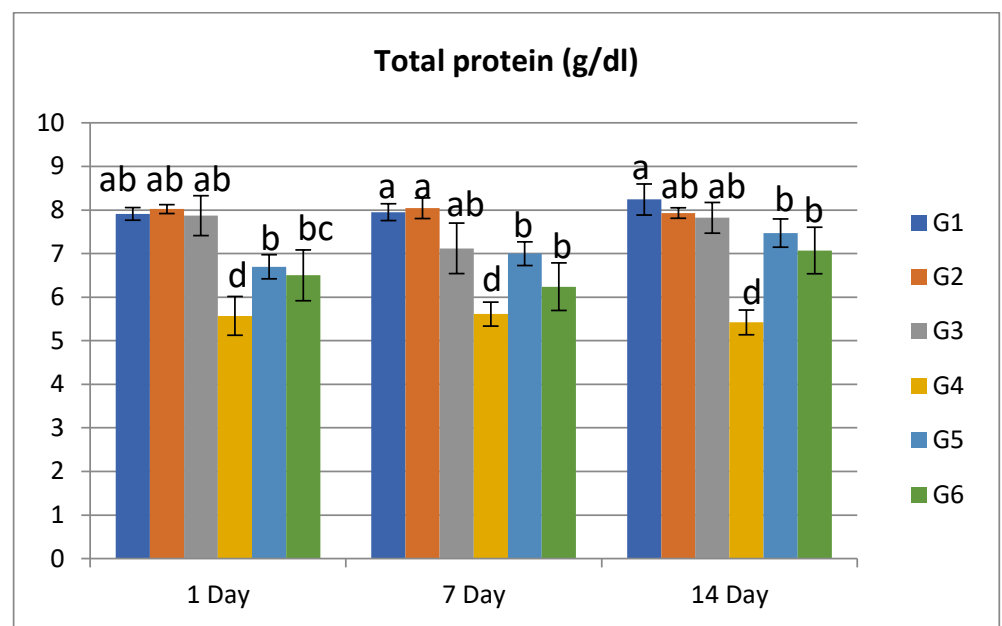

Fig. 6: G (1): Control G (2): Prebiotic G (3): Sly G (4): $\mathrm{Ccl}_{4} \mathrm{G}$ (5): Prebiotic+Ccl$_{4} \mathrm{G}$ (6): $\mathrm{Sly}+\mathrm{Ccl} 4$.

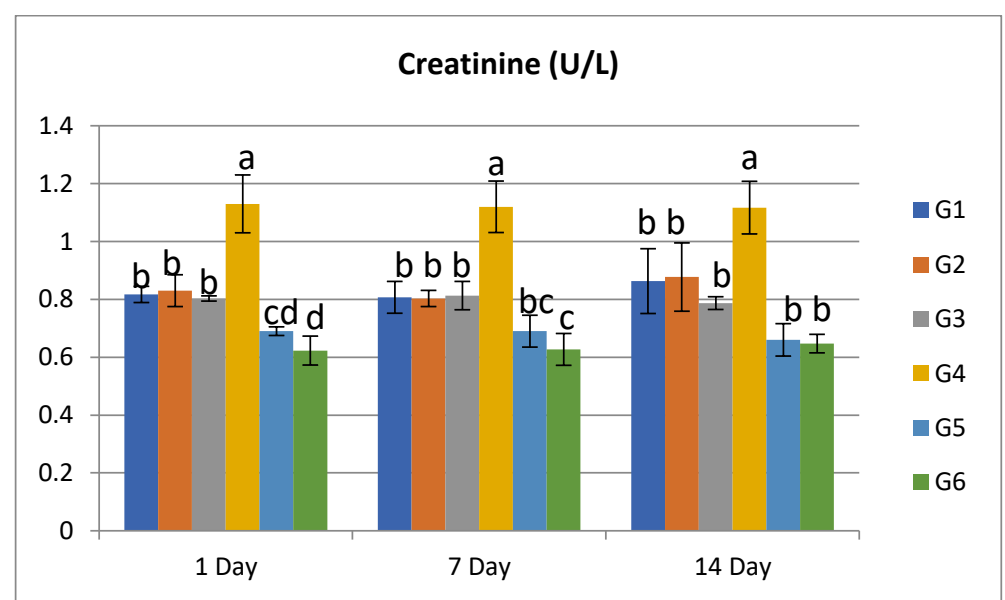

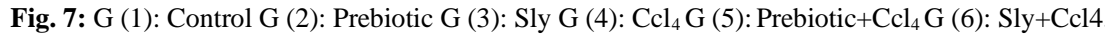




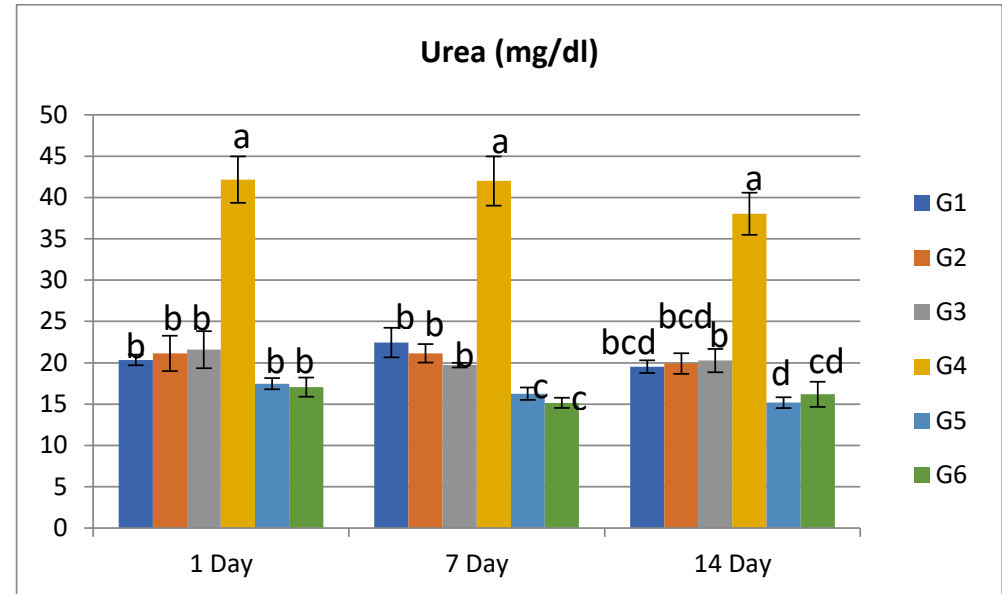

Fig. 8: G (1): Control G (2): Prebiotic G (3): Sly G (4): $\mathrm{Ccl}_{4} \mathrm{G}$ (5): Prebiotic+Ccl $_{4}$ G (6): $\mathrm{Sly}+\mathrm{Ccl} 4$

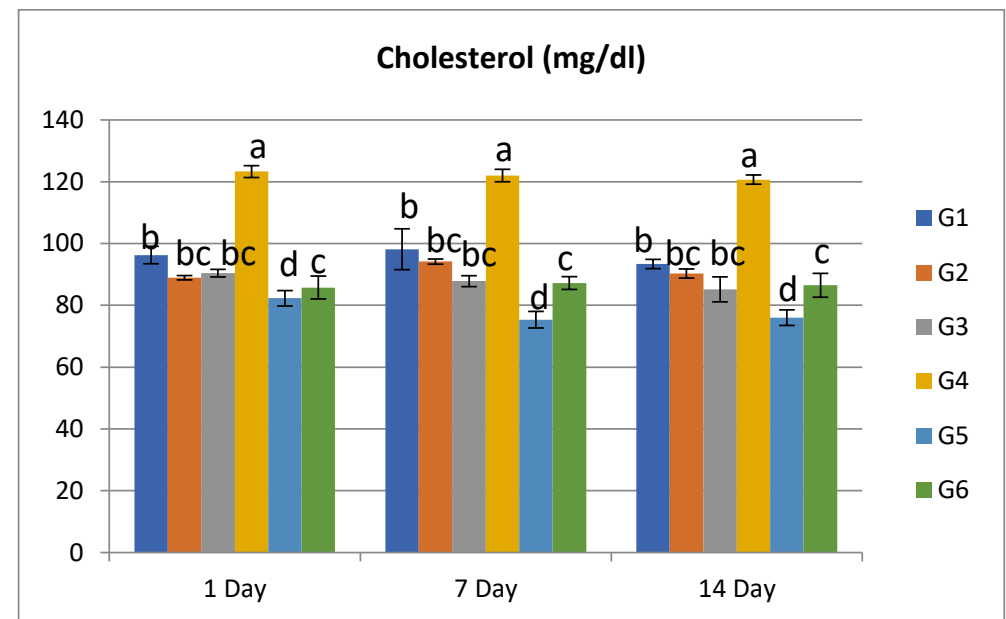

Fig. 9: G (1): Control G (2): Prebiotic G (3): SLY G (4): $\mathrm{CCL}_{4} \mathrm{G}$ (5): Prebiotic+CCL ${ }_{4} \mathrm{G}$ (6): SLY+CCL4.

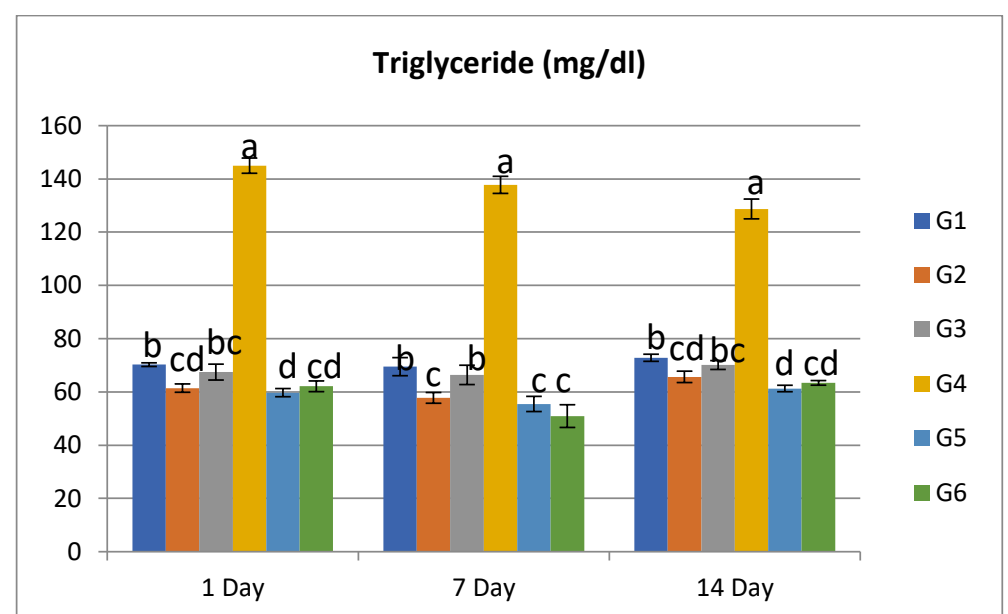

Fig. 10: G (1): Control G (2): Prebiotic G (3): Sly G (4): $\mathrm{Ccl}_{4} \mathrm{G}$ (5): Prebiotic+Ccl $_{4}$ G (6): $\mathrm{Sly}+\mathrm{Ccl}_{4}$. 


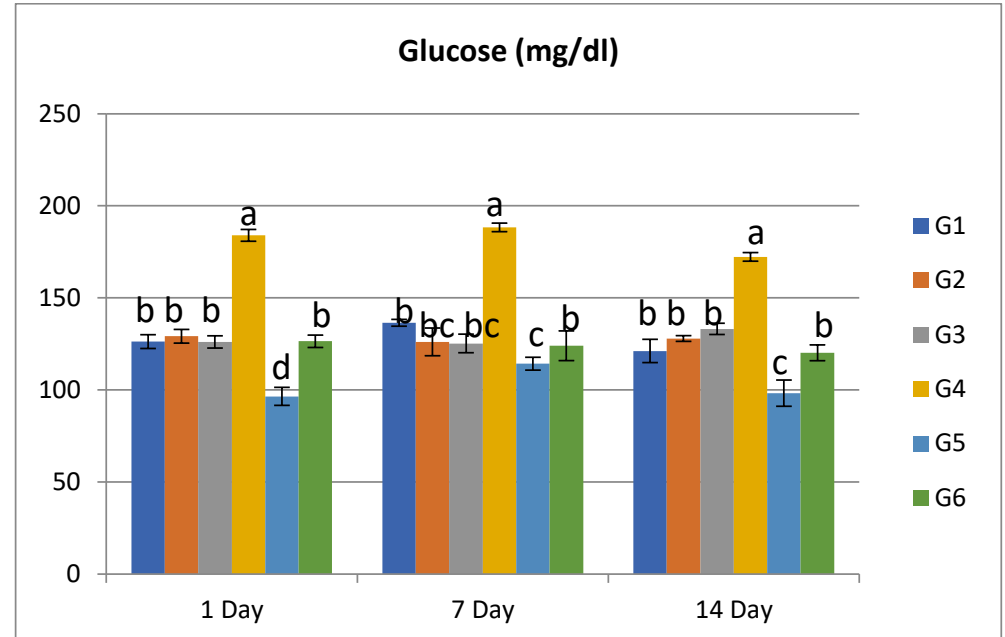

Fig. 11: G (1): Control G (2): Prebiotic G (3): Sly G (4): $\mathrm{Ccl}_{4} \mathrm{G}$ (5): Prebiotic+Ccl $_{4} \mathrm{G}$ (6): $\mathrm{Sly}+\mathrm{Ccl} 4$.

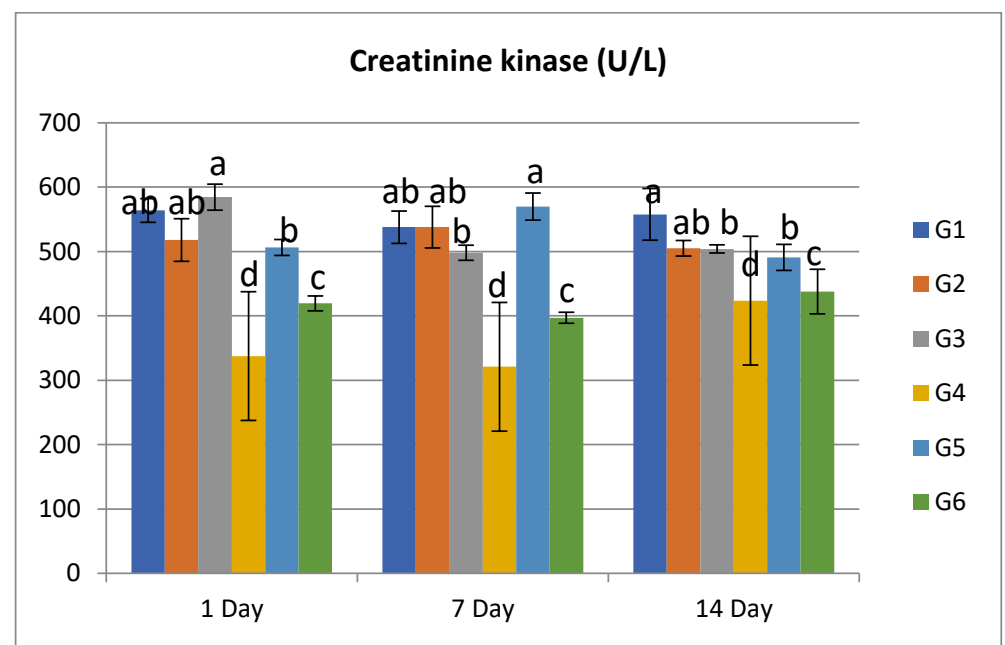

Fig. 12: G (1): Control G (2): Prebiotic G (3): $\operatorname{Sly~G~(4):~} \mathrm{Ccl}_{4} \mathrm{G}$ (5): $\operatorname{Prebiotic}_{+} \mathrm{Ccl}_{4} \mathrm{G}$ (6): $\mathrm{Sly}+\mathrm{Ccl} 4$.

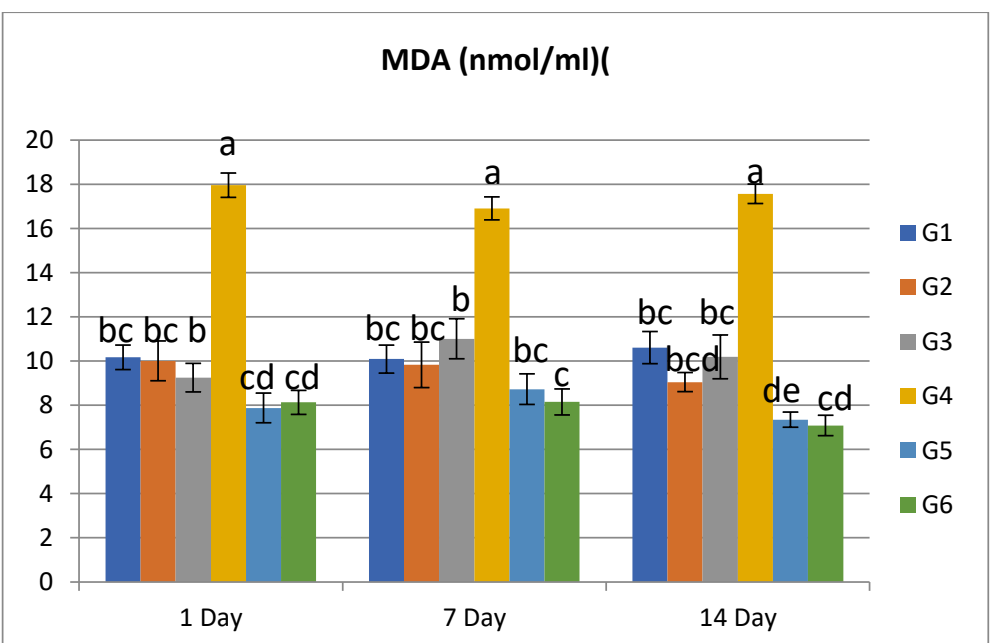

Fig. 13: G (1): Control G (2): Prebiotic G (3): $\operatorname{Sly~G~(4):~} \mathrm{Ccl}_{4} \mathrm{G}$ (5): Prebiotic+Ccl $_{4}$ G (6): $\mathrm{Sly}+\mathrm{Ccl} 4$. 


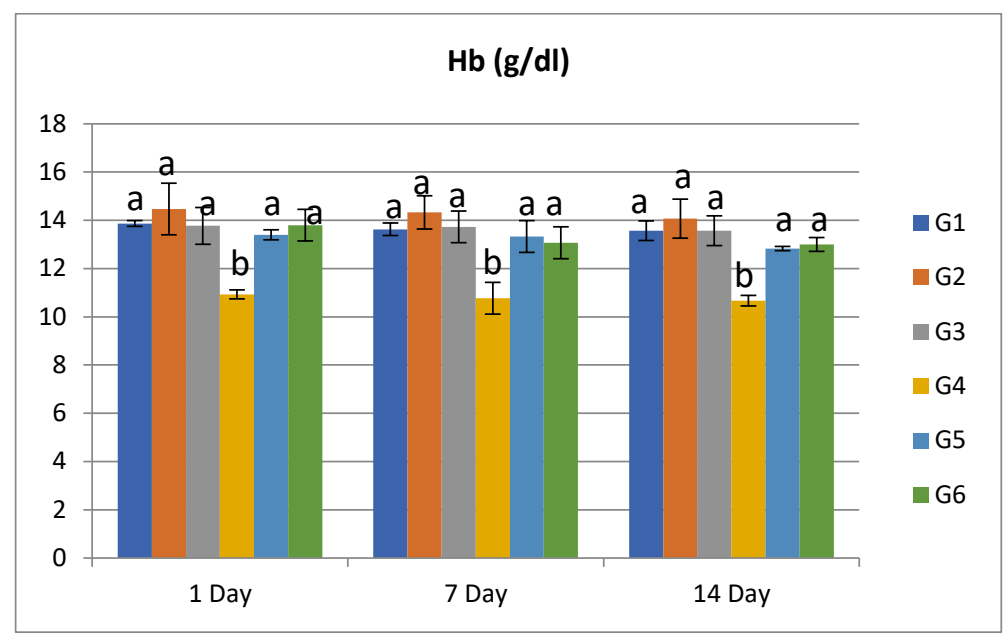

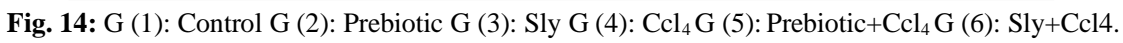

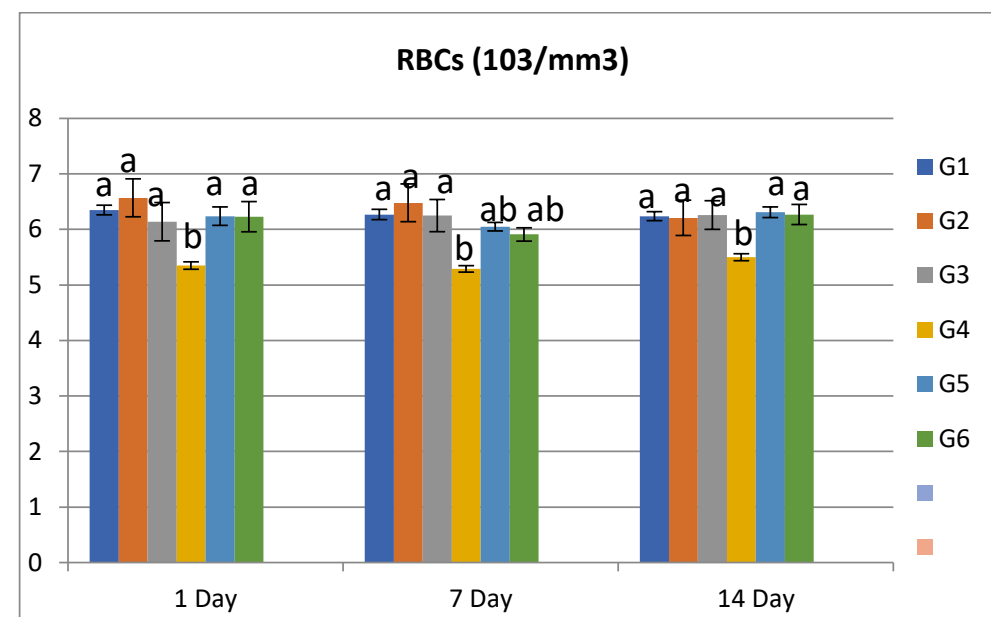

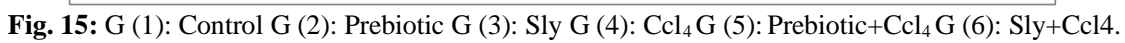

(A)

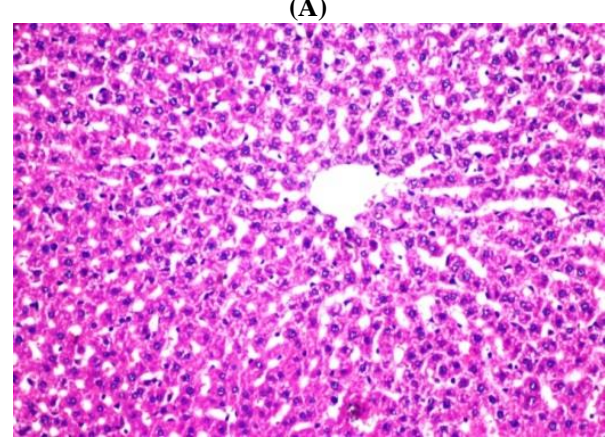

(C)

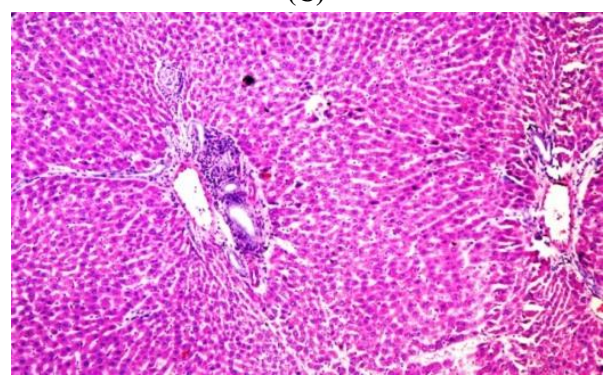

(E)

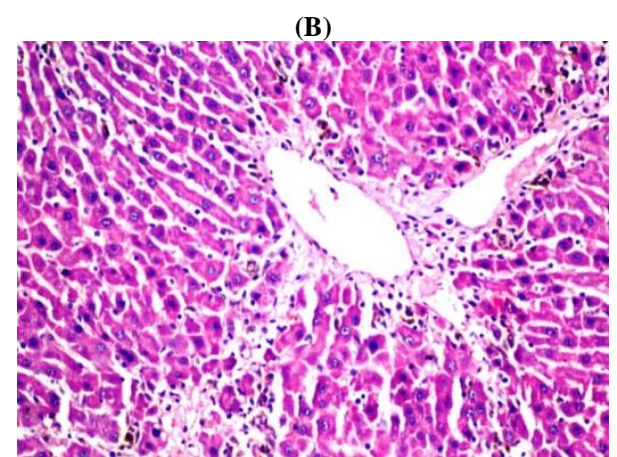

(D)

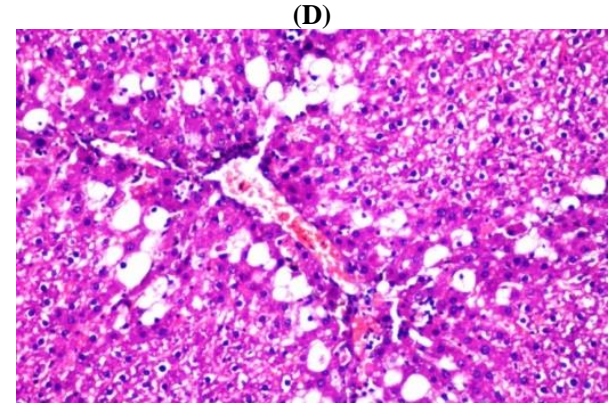

(F) 


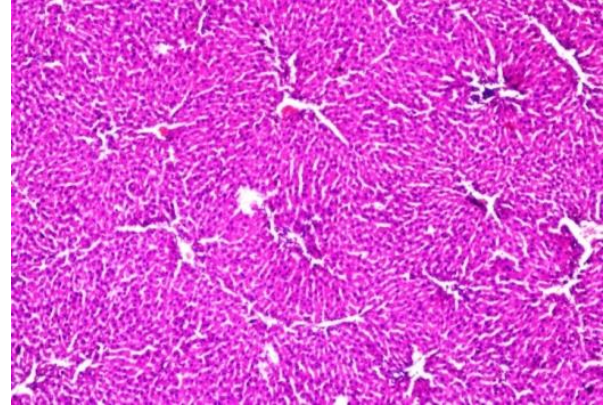

(G)

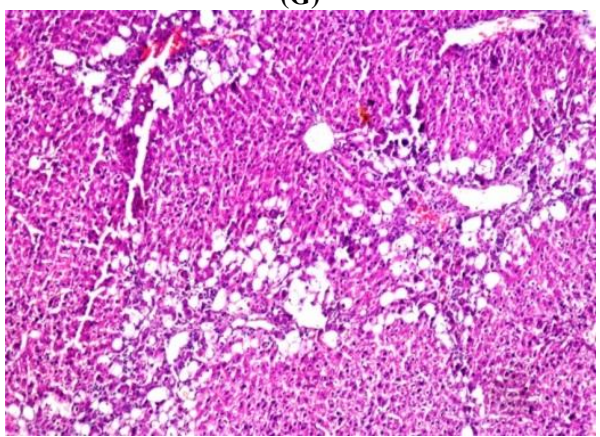

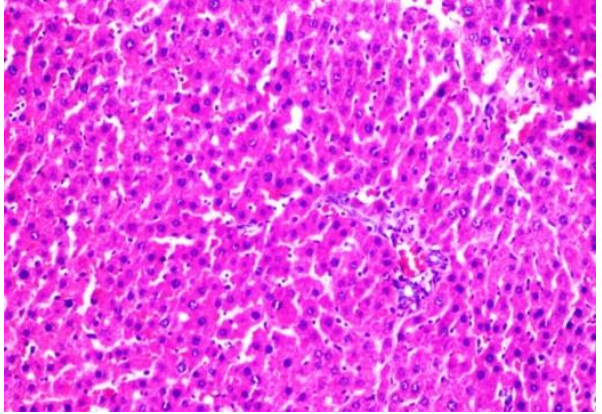

(H)

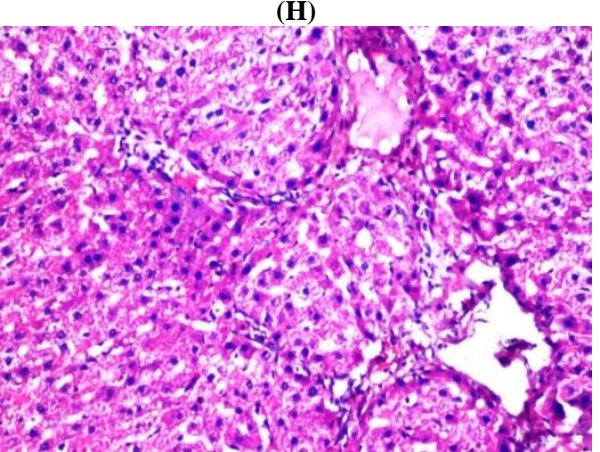

(I)

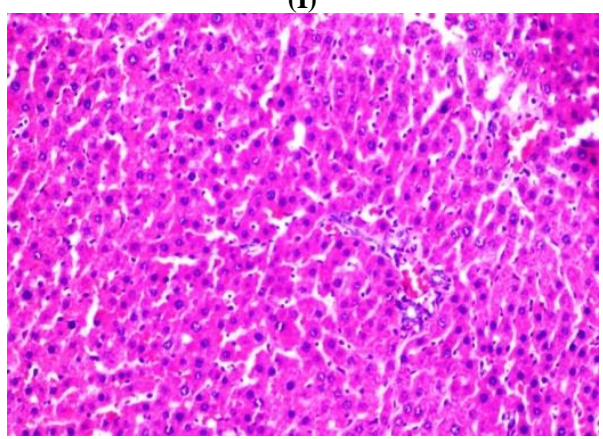

Fig.16: Histopathological Changes in Liver Sections After with Carbon Tetrachloride, Prebiotic and Silymarin A: Liver Sections from A Control, Prebiotic and Silymarin Rat Show Normal Histological Structure of Central Vein and Surrounding Hepatocytes in the Parenchyma .B,: CCL4 Rat Shows Steatosis with Inflammatory Cells Infiltration in in the Hepatic Capsule at First Day. C: CCL4 Rat Shows Massive Inflammatory Cells Infiltration in the Portal Area with Dilatation in Portal Vein at Fourteenth Day. D: Prebiotic-CCL4 Rat Shows Diffuse Centrilobular Vacuolization And Necrosis in the Hepatocytes at First Day. E: Prebiotic-CCL4 Rat Shows Very Few Inflammatory Cells Infiltration in the Portal Area at Seventh Day. F: Prebiotic-CCL4 Rat Shows Normal Histopathological Structure. G: SLY -CCL4 Rat Shows Centrilobular Vacuolar Degeneration in the Hepatocytes at First Day. H: SLY CCL4 Rat Shows Few Inflammatory Cells Infiltration and Fine Fibroblastic Cells Dividing the Parenchyma Into Tubules at Seventh Day. I: SLY -CCL4 Rat Shows Normal Histopathological Structure.

(A)

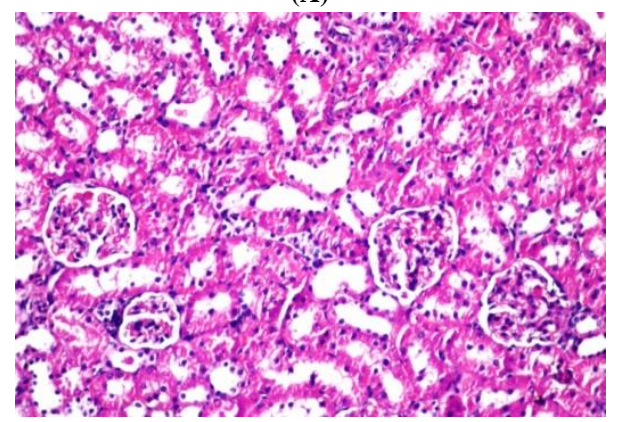

(C)

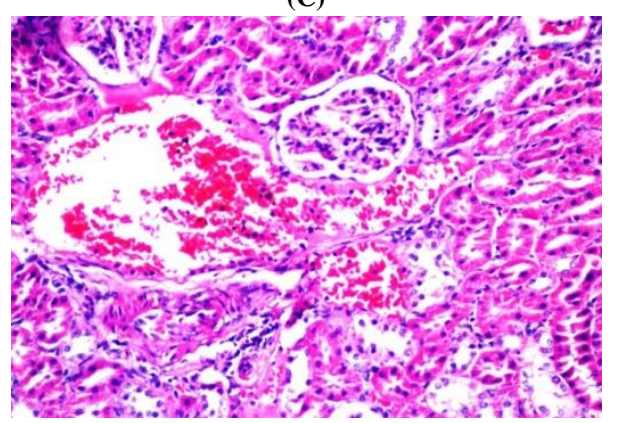

(B)

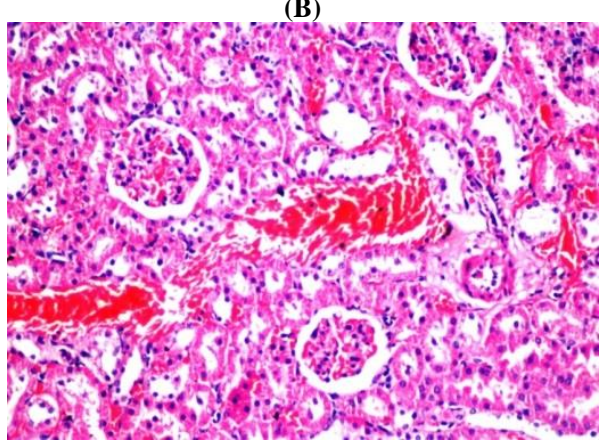

(D)

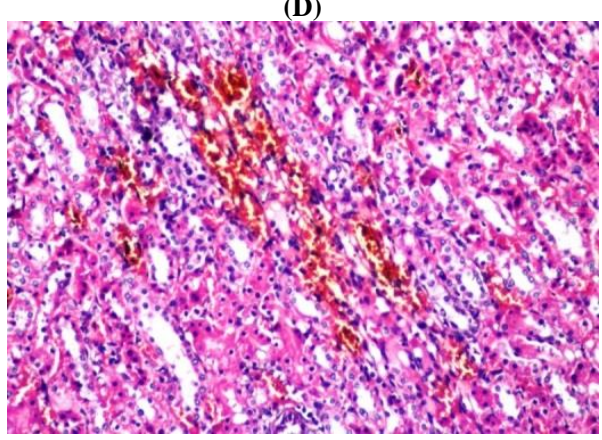


(E)

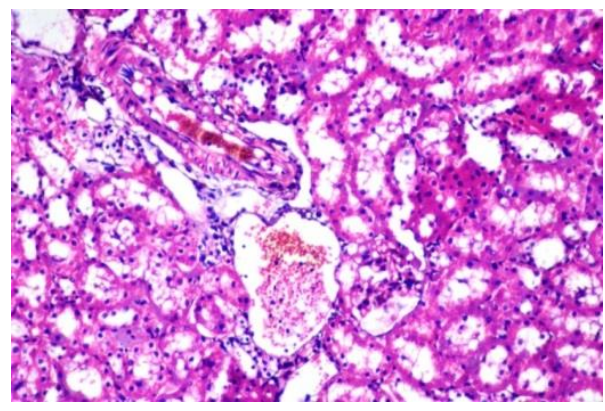

(G)

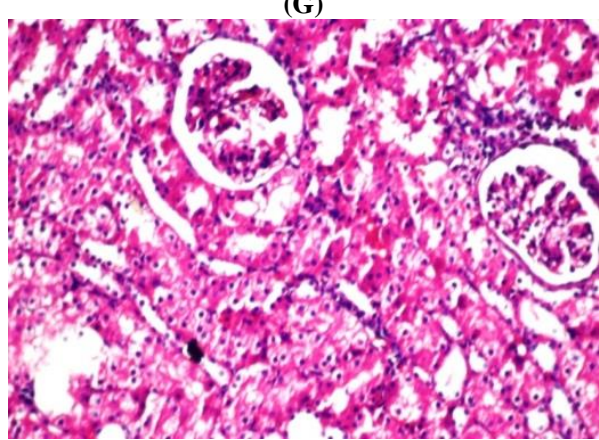

(F)
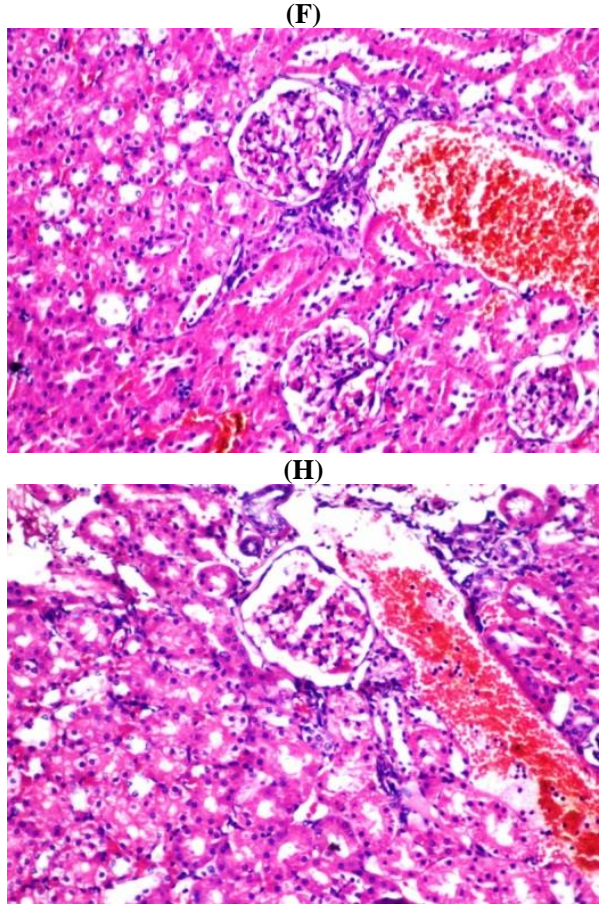

Fig. 17: Histopathological Changes in Kidney Sections after with Carbon Tetrachloride, Prebiotic and Silymarin A: Kidney Sections from A Control, Prebiotic and Silymarin Rat Show Normal Histological Structure of Glomeruli and Tubules.B: CCL4 Rat Shows Congestion in Cortical Blood Vessels at First and Seventh Day. C: CCL4 Rat Focal Haemorrhagic In Between the Tubules at Cortex at Fourteenth Day. D: Prebiotic-CCL4 Rat Shows Focal Haemorrhage in the Corticomedullary Portion between the Tubules and Improve Glomeruli at First Day. E: Prebiotic-CCL4 Rat Shows Vacuolar Degeneration Associated with Congestion in the Blood Vessels in the Tubular Lining Epithelium at the Cortex at Seventh Day. F: Prebiotic-CCL4 Rat Shows Congestion in the Cortical Blood Vessels and Normal Histopathological Structure of Glomeruli. G: SLY -CCL4 Rat Shows Swelling in the Tubular Lining Epithelium at the Cortex of First Day. H: SLY -CCL4 Rat Shows Congestion in the Cortical Blood Vessels at Seventh Dayand Fourteenth Day

\section{Results}

\subsection{Serum biochemical analysis}

As shown in Figures (1-8)

Carbon tetrachloride induced hepatotoxicity and nephrotoxicity as demonstrated by the elevation of serum liver and kidney biomarker. The AST, ALT, ALP, total bilirubin, urea and creatinine were substantially increased $(\mathrm{p} \leq 0.05)$ in response to carbon tetrachloride treatment and significantly decreased of total protein, albumin and creatinine kinase (Fig.12) compared to those of control rats. In contrast, these parameters were significantly reduced $(\mathrm{p} \leq 0.05)$ when carbon tetrachloride treated-rats were administrated prebiotic, silymarin compared to the carbon tetrachloride group. These data suggested that when prebiotic compared with silymarin have the same protection.

\subsection{Hepatic oxidative damage parameter}

The effects of carbon tetrachloride intoxication and treatment with prebiotic and silymarin on lipid peroxidation is shown in Figure 13. Carbon tetrachloride intoxicated rats showed significant increases $(\mathrm{P} \leq 0.05)$ in MDA compared to those of control rats. However, the toxic effects of carbon tetrachloride on hepatic MDA were significantly $(\mathrm{P} \leq 0.05)$ reduced by administration of prebiotic or SLY alone, but these values were still significantly different $(\mathrm{P} \leq 0.05)$ than the control values.

\subsection{Lipid profile}

The effects of prebiotic, silymarin, carbon tetrachloride intoxication and treatment with prebiotic and silymarin on lipid profile (cholesterol and triglyceride) are shown in Figure (9-10) .Prebiotic have a significance decrease on triglyceride compared to control rats. Carbon tetrachloride intoxicated rats showed significant increases $(\mathrm{P} \leq 0.05)$ in cholesterol and triglyceride compared to control rats, however the toxic effects of carbon tetrachloride were significantly $(\mathrm{P} \leq 0.05)$ restored by administration of prebiotic or silymarin.

\subsection{Glucose level}

Carbon tetrachloride caused significant increase $(\mathrm{P} \leq 0.05)$ in level of glucose concentration, which shown in Figure $(11)$. Treatment with prebiotic or silymarin significantly decreased glucose concentration compared to carbon tetrachloride rats.

\subsection{Hemoglobin concentration and RBCs}

The effects of carbon tetrachloride toxicity and treatment with prebiotic or silymarin on hemoglobin concentration and RBCs are shown in Figure (14-15). Carbon tetrachloride group rats showed significant increases $(\mathrm{P} \leq 0.05)$ in hemoglobin concentration and RBCs compared to those of control rats. However, the toxic effects of carbon tetrachloride on hemoglobin concentration and RBCs were significantly $(\mathrm{P} \leq 0.05)$ reduced by administration of prebiotic or silymarin.

\subsection{Histopathological findings}


Liver sections of control saline-treated rats had uniform polyhedral hepatocytes with normal sinusoids and central veins. In contrast, we observed portal vein congestion, massive inflammatory cells infiltration in the portal area with dilatation in portal vein carbon tetrachloride -treated rats at first, seventh and fourteenth day after end of administration. Prebiotic, silymarin restored to the normal hepatic architecture (Fig.16).

Control rats had normal glomeruli and renal tubular epithelia. In contrast, carbon tetrachloride induced toxicity and proved by congestion in cortical blood vessels, focal haemorrhagic in between the tubules at cortex and tubular vacuolization. In addition, carbon tetrachloride -treated rats exhibited moderate tubular dilatation and inflammatory cell infiltration at first, seventh and fourteenth day after end of administration. Treatment prebiotic or silymarin caused a notable recovery of the histopathological appearance after carbon tetrachloride induced renal injury (Fig.17).

\section{Discussion}

\subsection{Effect on liver function}

Carbon tetrachloride induced hepatocellular damage as fatty degeneration, fibrosis and impairment of liver function. Alanine aminotransferase and aspartate aminotransferase are hepatic enzymes that are released into the blood stream when liver cell are damaged (Fujii 1997) and alkaline phosphatase (Sanmugopriya and Venkataraman 2006). Rise in the level of total bilirubin than normal must have been due to liver damage and fibrosis (Shukla and Bhatia, 2010), also decreased serum total protein and albumin level and these may result in decreased hepatic ability to synthesize protein. Significant decrease in albumin had been associated with active cirrhosis and biliary liver damages (Shukla and Bhatia, 2010).Our findings are in accordance with Batool et al., (2017) and Otrubová et al., (2018) Prebiotic induced a regeneration effect on hepatocytes which manifested by a significant decrease liver function compared to carbon tetrachloride. These results are in accordance with Daubioul et al., (2005) who reported that the effect daily ingestion of oligofructose or maltodextrine in seven patients with nonalcoholic steatohepatitis, oligofructose decreased significantly serum aminotransferases, aspartate aminotransferase after 8 weeks .Another similar results were obtained by Liu et al., (2019) showed that plasma aspartate aminotransferase and alanine aminotransferase activities significantly decreased after supplementation with resistant maltodextrin in high-fat diet-fed rats. Prebiotic have no adverse effect on liver function (Préstamo et al., 2003, El-Mahmoudy et al., 2014)

In this study, administration of silymarin did not have remarkable change on liver function tests compared to control (Lamofen 2007 ; Shaarawy et al., 2009). The hepatoprotective activity of silymarin can be explained based on antioxidant properties due to the phenolic nature of flavonolignans, also acts through stimulating liver cells regeneration and cell membrane stabilization to prevent hepatotoxic agents from entering hepatocytes (Fraschini et al.,2002). Silymarin and carbon tetrachloride restored the increase in liver function. The results come with agreement with Freitag et al., (2015), Kim et al., (2016), De Avelar et al., (2017) and Famouri et al., (2017).

\subsection{Effect on kidney function}

In the present study, carbon tetrachloride induced nephrotoxicity represented by significant increase level of creatinine and urea (Kaneko et al., 1997). Altitude of urea and creatinine levels in the blood was taken as the index of nephrotoxicity Alatriste et al., (2014). Our findings are in accordance with Awodele et al., (2015), Kamal (2015) and Mazani et al., (2018).

Prebiotic restored the carbon tetrachloride intoxication by decreasing serum of creatinine and urea. Prebiotic altered the intestinal environment and suppressed uremic toxin production consequently suppressing the renal disorder and tubulointerstitial fibrosis progression Sueyoshi et al., (2019). This results come consistent with Koguchi et al., (2004) investigated that dietary fiber suppressed the elevation of creatinine and urea nitrogen concentrations in serum by attenuating the absorption of dietary adenine. Tayebi Khosroshahi et al., (2014) suggested that lactulose administration in chronic kidney disease patients could significantly decreased urea levels, creatinine. Prebiotic had insignificant change on serum level of creatinine and urea compared to control El-Mahmoudy et al., (2014). Prebiotic appeared to have the same result when compared with silymarin.

Silymarin have similar effect to normal control on in kidney function (Turgut et al., 2008).Silymarin followed by carbon tetrachloride caused a significant decrease in serum level of creatinine and urea compared to carbon tetrachloride. Antioxidant and anti-inflammatory properties of silymarin may also have protective role against nephropathic processes (Kren and Walterova 2005). Silybin has been found to stimulate kidney cells in a similar manner to that seen in liver cells. Administration of silybin prior to or following the chemicalinduced injury has prevented or reduced nephrotoxic effects (Sonnenbichler., et al 1999). This results are consistent with El-Shitany et al., (2008) recorded that pretreatment of adriamycin treated rats with silymarin resulted in a significant decrease in the plasma creatinine and urea. Another similar results was obtained by Momeni et al., (2015) evaluated that silymarin decrease serum creatinine induced by cisplatin in adult patients with malignancy. The results inconsistent with Shahbazi et al., (2015) who illustrated that silymarin tablets could not prevent cisplatin-induced urine electrolyte wasting or renal function impairment.

\subsection{Effect on lipid profile}

There was a significant increase in serum total cholesterol and triglyceride concentration in rats administration carbon tetrachloride compared to control rat (Agatemor et al., (2018), Otrubová et al., (2018) and Shahwan et al., (2018)).

Prebiotic showed a benefit effect by significant decrease on triglyceride but there no significant difference in cholesterol level compared to control rat .Our results come in agreement with Figurska-Ciura et al., (2007) reported that resistant starch decreased triacyloglycerol level while the total cholesterol level, in serum was not affected. Kishimoto et al., (2007) indicate that resistant maltodextrin ingested with fatty meals suppresses the postprandial elevation of blood triacylglycerol levels. Jarosz et al., (2013) reported that $\alpha$-Cyclodextrin was shown to no significant changes in cholesterol levels and lowered acute postprandial blood triglyceride levels significantly. Gargari et al., (2015) indicated that resistant Starch had no significant change in total cholesterol and low-density lipoprotein.

Pretreatment carbon tetrachloride with prebiotic showed a significant decrease on serum of cholesterol and triglyceride. The decrease of cholesterol may be related to assimilation by bacteria that a prebiotic stimulates their growth and/or activity in the colon as Bifidibacteria and Lactobacilli (Pereira and Gibson 2002).The obtained results come in agreement with that obtained by Liu et al., (2019) suggested that resistant maltodextrin significantly reduced the increased plasm total cholesterol and triglycerides in high diet fed rat.

Silymarin have the same remarkable change compared to control (Nassuato et al., 1991 and Škottová et al., 1998) .Silymarin had protective effect against toxicity of carbon tetrachloride on lipid profile (cholesterol and triglyceride) represented by significant decrease on 
serum level of cholesterol and triglyceride (Škottová et al., 2003; Šobolová et al. 2006) reported that feeding rats by silymarin leads to significant decrease of total plasma and liver cholesterol through the inhibition of intestinal cholesterol absorption. Also Heidarian and Rafieian-Kopaei (2012) studied that plasma total cholesterol, and triglyceride levels significantly decreased $(\mathrm{p}<0.05)$ due to silymarin treatment in hyperlipidimic rat.

\subsection{Effect on serum glucose level}

The present investigation study showed that, carbon tetrachloride caused a significant increase on serum glucose level compared to control rat (Ozturk et al., 2012 and Adeneye et al., 2015). Prebiotic restored increase glucose concentration that induced by carbon tetrachloride. The obtained results come agreement with Hashizume et al., (2012) suggested that continuous ingestion of resistant maltodextrin improve glucose on humans with metabolic syndrome. Aliasgharzadeh et al., (2015), who that recorded maltodextrin lowered fast glucose in type 2 diabetic patients in a randomised controlled clinical trial. Behrouz et al., (2017) determined the decreased effect of maltodextrin on glycemic parameters in the patients with non-alcoholic fatty liver disease. Prebiotic have similar change to normal control on serum glucose (Gargari et al., 2015 and Carla et al., 2011).

Silymarin and carbon tetrachloride induced a significant decrease compared to carbon tetrachloride toxicity. The findings come in accordance to Narayanamurthy et al., (2014) and Voroneanu et al., (2016) revealed that silymarin seems to have anti-inflammatory properties, significant reduction in fasting blood glucose levels of Type 2 diabetes mellitus. Silymarin had no remarkable change on serum glucose compared to control rat.

\subsection{Effect on serum creatinine kinase level}

In this study, Carbon tetrachloride caused a significant decrease on creatinine kinase enzyme activity compared to control .On other hand prebiotic appeared to have a remarkable effect by reverse carbon tetrachloride toxicity on creatinine kinase activity (Pacheco et al., 2009 and Gabardo et al., 2015) .Our results come in agreement with McKenzie et al., (2003) and Ribreiro et al., (2004) indicated that resistant starch (prebiotic) increase serum creatine kinase activity in equine recurrent exertional rhabdomyolyis in horse. Treatment with silymarin was effective in creatine kinase of carbon tetrachloride intoxication. Our results come in consistent with that attained by Taghiabadi et al., (2012) said that silymarin may play benefit effects against cardiotoxicity of acreolin on creatinine kinase.

\subsection{Effect on serum L-malondialdehyde (MDA) level}

Carbon tetrachloride caused a significant increase in serum L-malondialdehyde (Haghi et al., (2014), Shen et al., (2015) and Nie et al., (2015).The effect of prebiotic and carbon tetrachloride induced a significant decrease malondialdehyde. These results come in agreement with that attained Aliasgharzadeh et al., (2015) recorded that the decreased effects of resistant dextrin on malondialdehyde in type 2 diabetic patients in a randomised controlled clinical trial. Prebiotic had statistically similar to the control Rishi et al.,(2009) .

Silymarin reduced the increase of on serum L-malondialdehyde that induced by carbon tetrachloride toxicity. These results consistent with Mansour et al., (2006) evaluated the protective effect of silymarin on Cisplatin induced significant decrease on serum Lmalondialdehyde in rats. Oda, Samah and El-Ashmawy (2012) revealed that silymarin, improved the mercury-induced serum malondialdehyde. Silymarin showed insignificant change on serum L-malondialdehyde

\subsection{Effect on hematological picture}

Carbon induced a significant decrease in red blood cell count and hemoglobin content El-Bialy et al., (2019).Prebiotic and carbon tetrachloride group caused improvement on hemoglobin concentration, and red blood cell count compared to carbon tetrachloride. Our findings agreement with that obtained by Shih et al., (2007) proved that high resistant starch in Japonica rice diet reduced hemoglobin level of induced diabetic rats. Farhangi et al., (2016) showed beneficial effects of oligofructose-enriched chicory on the improvement of hematological parameters in patients with type 2 diabetic mellitus. Prebiotic was similar significant to normal control rats on hemoglobin content and red blood cell count. The results were consistent with Wu et al., (2018) stated that steady-fiber granule (resistant maltodextrin, white kidney bean extract, mulberry leaf extract, and niacin-bound chromium complex) showed no adverse effects of hematology in male and female rats.

Also, silymarin improved carbon tetrachloride intoxication on hemoglobin and red blood cell and these results consistent with Bouhalit et al., (2017) demonstrated that silymarin extract effectively improved heamatotoxicity caused by nickel. Silymarin had no significance change compared to normal control rat.

\subsection{Histopathological changes}

Liver examination of carbon tetrachloride showed hepatosteatosis with inflammatory cells infiltration (Deng et al., (2012) Cetinkaya et al., (2013) Laouar et al., (2017).

Histopathological evaluation of liver confirmed biochemical data of prebiotic and carbon tetrachloride group by improvement the histological feature of hepatocytes that induced by carbon tetrachloride. There was very few inflammatory cells infiltration in the portal area. Our results come in agreement with Liu et al., (2019) reported that supplementation of resistant maltodextrin effectively reduced the histopathological changes in the liver of height fructose diet-fed rats.

Liver examination of silymarin and carbon tetrachloride had an important role by reducing pathologic damage degree compared to carbon tetrachloride. Pretreatment with silymarin markedly reduced the presence of deteriorated hepatic cell and heptoprotective evidenced by the absence of cellular necrosis and inflamation in liver section .These results consistent with Papackova et al., (2018) who suggested that necrosis the dominant cell death pathway in Acetaminophen or paracetamol intoxication which was partially preventable by silymarin pretreatment in histological examination. Liver examination of prebiotic group and silymarin group showed no significant difference on histopathological change compared to control.

Kidney examination was done after carbon on histological findings of kidney and illustrated a renal degeneration, necrosis congestion in cortical blood vessels and focal haemorrhagic in between the tubules at cortex (Adewole et al., (2007) Venkatanarayana et al., (2012) 
Kidney examination of prebiotic and carbon tetrachloride group proved renal-protection effect of prebiotic on nephrotoxicity of carbon tetrachloride. The obtained results come in agreement with that Smazal et al., (2013) indicated that dietary resistant starch showed mild deterioration in renal proximal of diabetic rats type 1. Koh et al., (2015), revealed that resistant starch attenuated diabetes-mediated damage on histological scoring of the kidney.

Kidney examination of silymarin and carbon tetrachloride group had improvement effect on kidney features with some dilatation of their lumen. Our results are similar to that obtained by Cecen et al., (2011) investigated that silymarin significantly protected doxorubicininduced toxicities to the rat kidney by histopathological examination. Alcaraz -Contreras et al., (2016), who illustrated that silymarin improve the renal histopathological lesions of lead toxicity in rats. Kidney examination of prebiotic group and silymarin group illustrated no histopathological change.

\section{Conclusion}

The overall of data illustrated that carbon tetrachloride could induce severe tissue damage in the liver and kidney of rats. Our findings proved that prebiotic or silymarin has protective effect against carbon tetrachloride - damage in the liver and kidney, also improvement lipid profile, glucose level and hematological effect.

\section{References}

[1] Adeneye AA, Awodele O, Aiyeola SA and Benebo AS. (2015): Modulatory potentials of the aqueous stem bark extract of Mangifera indica on carbon tetrachloride-induced hepatotoxicity in rats. Journal of Traditional and Complementary Medicine.5:106-115

[2] Agatemor UM, Nwodo OF.C, Adejoh IP and Anosike CA. (2018): Protective effect of cucumis sativus on carbon tetrachloride CCl4-induced liver damage in rats. Asian Journal of Biochemistry, 13: 22-29.

[3] Alatriste PM, Arronte RU, Espinosa CG, and Cuevas MDL (2014): Effect of probiotics on human blood urea levels in patients with chronic renal failure. Nutr Hosp.; 29(3):582-590.

[4] Alcaraz-Contreras Y, Mendoza-Lozano RP, Martínez-Alcaraz ER, Martínez-Alfaro M, Gallegos-Corona MA, Ramírez-Morales MA and VázquezGuevara M.A.(2016): Silymarin and dimercaptosuccinic acid ameliorate lead-induced nephrotoxicity and genotoxicity in rats.Human \& Experimental Toxicology Apr; 35(4):398-403.

[5] Aliasgharzadeh A, Dehghan P, Pourghassem-Gargari B. and Asghari-Jafarabadi M. (2015): Resistant dextrin, as a prebiotic, improves insulin resistance and inflammation in women with type 2 diabetes: a randomised controlled clinical trial. Br J Nutr; 113(02):321-30.

[6] Awodele O, Adeneye AA, Aiyeola SA, Benebo AS. (2015): Modulatory effect of Mangifera indica against carbon tetrachloride induced kidney damage in rats. Interdiscip Toxicol. Dec; 8(4): 175-183.

[7] Banchroft, J.D.; Stevens, A. and Turner, D.R. (1996): Theory and practice of histological techniques Fourth ED. Churchil Livingstone ,New York , London, San Francisco, Tokyo.

[8] Batool R, Khan M.R and Majid M. (2017): Euphorbia dracunculoides L. abrogates carbon tetrachloride induced liver and DNA damage in rats. BMC Complement Altern Med. Apr 20; 17(1):223.

[9] Behrouz V, Jazayeri S, Aryaeian N, Zahedi M.J and Hosseini F.(2017): Effects of Probiotic and Prebiotic Supplementation on Leptin, Adiponectin, and Glycemic Parameters in Non-alcoholic Fatty Liver Disease: A Randomized Clinical Trial. Middle East J Dig Dis. Jul; 9(3):150-157.

[10] Bouhalit S, Kechrid Z. and Elfeki A. (2017): The effect of silymarin extract from Silybum marianum against nickel-induced hematotoxicity and nephrotoxicity an male albino Wistal rats.International Journal of pharmacy and pharmaceutical sciencesVol: 9.issue 8:84-89.

[11] Carla M. Brites Maria J. (2011): Mazie and resistant starch enriched breads reduce postprandandial glycemic responses in rats. Volume 31, Issue 4, Pages 302-308

[12] Cecen, E.; Dost, T.; Culhaci, N.; Karul, A.; Ergur, B. and Birincioglu, M. (2011): Protective effects of silymarin against doxorubicin-induced toxicity. Asian Pac J Cancer Prev. 12(10):2697-704.

[13] Cetinkaya, A; Kantarceken, B; Bulbuloglu, E; Kurutas, E.B; Ciralik, H and Atli, Y.(2013): The effects of L-carnitine and N-acetylcysteine on carbontetrachloride induced acute liver damage in rats. Bratisl Lek Listy.; 114(12):682-8.

[14] Comelli MC, Mengs U, Schneider C, Prosdocimi M. (2007) toward the definition of the mechanism of action of silymarin: Activities related to cellular protection from toxic damage induced by chemotherapy. Integr Cancer Ther; 6:20-9.

[15] Daubioul C.A, Horsmans Y, Lambert P,Danse E. ,Delzenne N.M.(2005): Effects of oligofructose on glucose and lipid metabolism in patients with nonalcoholic steatohepatitis: results of a pilot study. Eur J Clin Nutr. May; 59(5):723-6.

[16] de Avelar C.R, Pereira E.M, de Farias Costa P.R, de Jesus R.P, de Oliveira L.P.M.(2017): Effect of silymarin on biochemical indicators in patients with liver disease: Systematic review with meta-analysis. World J Gastroenterol. Jul 21; 23(27):5004-5017.

[17] Delzenne N. and Reid G. (2009): No causal link between obesity and probiotics. Nat Rev Microbiol 7: 901.

[18] Deng J.S, Chang Y.C. Wen C.L, Liao J.C, Hou W.C, Amagaya S, Huang S.S and Huang G.J.(2012): Hepatoprotective effect of the ethanol extract of Vitis thunbergii on carbon tetrachloride-induced acute hepatotoxicity in rats through anti-oxidative activities. Journal Ethnopharmacol. Aug 1; 142(3):795-803.

[19] Duncan D.B. (1955): Multiple range and multiple Ftests. Biometrics 11:1 42.

[20] El Bialy, B.E; El-Boraey, N.G; Hamouda, R.A and Abdel- Daim,M.M.(2019): Comparative protective effects of Spirulina and Spirulina supplemented with thiamine against sub-acute carbon tetrachloride toxicity in rats. Biomedical \& Pharmacology Journal, June Vol. 12(2), p. 511-525.

[21] El-Mahmoudy A.M, Abdel-Fattah FA, Abd El-Mageid AD, and Gheith IM. (2014): Effect of the growth promotant Mannan-Oligosaccharide on the lipogram and organfunction profile in hyperlipidemic Albino rat. Rats American Journal of Phytomedicine and Clinical TherapeuticsISSN 2321 -2748 .

[22] El-Shitany N.A, El-Haggar S, and El-desoky K.(2008): Silymarin prevents adriamycin-induced cardiotoxicity and nephrotoxicity in rats. Food Chem Toxicol. Jul;46(7):2422-8.

[23] Englyst HN, Kingman SM, and Cummings JH. (1992): Classification and measurement of nutritionally important starch fractions. European Journal of clinical nutrition 46(2):33-55.

[24] Famouri F, Salehi MM, Rostampour N, Hashemi E, and AShahsanaee A.(2017): The effect of silymarin on non-alcoholic fatty liver disease of children.J Herbmed Pharmacol. ;6(1):16-20.

[25] Farhangi MA, Javid AZ, and Dehghan P. (2016): The effect of enriched chicory inulin on liver enzymes, calcium homeostasis and hematological parameters in patients with type 2 diabetes mellitus: A randomized placebo-controlled trial.Prim Care Diabetes. Aug; 10(4):265-71.

[26] Figurska-Ciura D, Orzeł D, Styczyńska M and Wacław L. (2007): The influence of RS4 resistant starch on wistar rats metabolism. Biochemical and lipid indices. Roczniki Państwowego Zakładu Higieny 58(1):1-6

[27] Fraschini F, Demartini G, and Esposti D. (2002): Pharmacology of silymarin. Clinical Drug Investigation 22(1), 51-65.

[28] Freitag AF, Cardia GF, da Rocha BA, Aguiar RP, Silva-Comar FM, Spironello RA, Grespan R, Caparroz-Assef SM, Bersani-Amado CA and Cuman, RK. (2015): Hepatoprotective Effect of Silymarin (Silybum marianum) on Hepatotoxicity Induced by Acetaminophen in Spontaneously Hypertensive Rats. Evid Based Complement Alternat Med.; 2015:538317. 
[29] Fujii T. (1997): Toxicological correlation between changes in blood biochemical parameters and liver histopathological findings. Journal of Toxicological Science; 22: 161-83.

[30] Gargari BP, Namazi N, Khalili M, Sarmadi B, Jafarabadi MA and Dehghan P.(2015): Is there any place for resistant starch, as alimentary prebiotic, for patients with type 2 diabetes? Complement Ther Med. Dec; 23(6):810-5.

[31] Gibson GR and Roberfroid MB. (1995): Dietary modulation of the colonic microbiota: introducing the concept of prebiotics. Journal of Nutrition 125, 1401-1412.

[32] Hahn G, Lehmann HH, Kurten M, Uebe H and Vogel G.(1968): On the pharmacology and toxicology of silymarin,an antihepatotoxic active principlefromSilybummarianum(L.)Gaertn.Arzneimitteloforschung.18:698-704.

[33] Haghi MEs, Dehghan G, Banihabib N, Zare S, Mikaili P and Panahi F.(2014): Protective effects of Cornus mas fruit extract on carbon tetrachloride induced nephrotoxicity in rats. Indian J Nephrol. Sep-Oct; 24(5): 291-296.

[34] Hashizume C, Kishimoto Y, Kanahori S, Yamamoto T,Okuma K. and Yamamoto K.(2012): Improvement effect of resistant maltodextrin in humans with metabolic syndrome by continuous administration. J Nutr Sci Vitaminol (Tokyo); 58(6):423-30.

[35] Heidarian E and Rafieian-Kopaei M. (2012): Effect of silymarin on liver phoshpatidate phosphohydrolase in hyperlipidemic rats. Bioscience Research, 9(2): 59-67,

[36] Jarosz PA, Fletcher E, Elserafy E, Artiss JD and Jen KL.(2013): The effect of $\alpha$-cyclodextrin on postprandial lipid and glycemic responses to a fatcontaining meal. Metabolism. Oct; 62(10):1443-7.

[37] Kamal S. (2015): The protective effect of curcumin on nephrotoxicity induced by carbon tetrachloride in rats. Journal of advances in life and Natural sciences, Vol. 1 (1), 22-29,

[38] Kaneko JJ. Clinical biochemistry of domestic animals. 5th ed. San Diego (CA): Academic Press, 1997.

[39] Kim SH, Oh, DS, Oh JY, Son TG, Yuk DY and Jung YS.(2016): Silymarin prevents restraint stress-induced acute liver injury by ameliorating oxidative stress and reducing inflammatory response. Molecules. Apr 1; 21(4):443.

[40] Kishimoto Y, Oga H, Tagami H, Okuma K and Gordon DT.(2007): Suppressive effect of resistant maltodextrin on postprandial blood triacylglycerol elevation. Eur J Nutr. Apr; 46(3):133-8.

[41] Kishimoto Y, Hayashi N, Yamada T, Yuba K and Yamamoto K. (2009): Favorable effect of resistant maltodextrin on postprandial blood Glucose, insulin and triglyceride levels. Jpn Pharmacol Ther, 37, 277-283.

[42] Khan MR, Rizvi W, Khan GN, Khan RA, Shaheen S. (2009): Carbon tetrachloride induced nephrotoxicity in rats: protective role of Digera muricata. J Ethnopharmacol; 122:91-99.

[43] Koh GY(2015): Resistant starch:implication in kidney health and vitamin D homeostasis in diabetes mellitus

[44] Koguchi T, Koguchi H, Nakajima H, Takano S, Yamamoto Y, Innami S, Maekawa A and Tadokoro T .(2004):Dietary fiber suppresses elevation of uric acid and urea nitrogen concentrations in serum of rats with renal dysfunction induced by dietary adenineInt J Vitam Nutr Res.74(4):253-63.

[45] KrenV and Walterova D. (2005): Silybin and silymarin- new effects and applications. Biomed Papers, 149(1):29-41.

[46] Lamfon H. (2007): Effect of silymarin against deltamethrin-induced histological and biochemical changes in liver of albino rats. Indian journal of experimental biology 3:165-169.

[47] Laouar A, Fahima K, Bourogaa E, and Amel Benamara A.(2017): Potential antioxidant properties and hepatoprotective effects of Juniperus phoenicea berries against $\mathrm{CCl} 4$ induced hepatic damage in rats. Asian Pacific Journal of Tropical Medicine 10(3) .

[48] Liu SH, Chiu C, Huang L, Chiang M.(2019): Resistant maltodextrin ameliorates altered hepatic lipid homeostasis via activation of AMP-activated protein kinase in a high-fat diet-fed rat model. Nutrients $29 ; 11(2)$.

[49] Mansour HH, Hafez HF, and Fahmy NM (2006): Silymarin modulates Cisplatin-induced oxidative stress and hepatotoxicity in rats. J Biochem Mol Biol. Nov 30; 39(6):656-61.

[50] Matsubara T, Mori S, Touchi A, Masuda Y, Takeuchi Y. Carbon tetrachloride-induced hepatotoxicity in rats: evidence for different susceptibilities of rat liver lobes. Jpn J Pharmacol. 1983 Apr; 33(2):435-45.

[51] Mazani M, Mahmoodzadeh Y, Chinifroush-Asl MM, Banaei S, Rezagholizadeh L, Mohammadnia A. (2018): Renoprotective effects of the methanolic extract of Tanacetum parthenium against carbon tetrachloride-induced renal injury in rats. Avicenna Journal Phytomedicien, Vol. 8, No. 4, Jul-Aug.

[52] McKenzie EC, Stephanie JV, Sandra MG and Joe DP.(2008): Effects of dietary starch,fat, and bicarbonate content on exercise responses and serum creatine kinase activity in equine recurrent exertional rhabdomyolysis. Journal of veterinary internal medicine. Volume 17 issue 5.

[53] Momeni A, Hajigholami A, Geshnizjani S and Kheiri S.(2015): Effect of silymarin in the prevention of cisplatin nephrotoxicity, a clinical trial study. J Clin Diagn Res. Apr; 9(4): OC11-OC13.

[54] Narayanamurthy U, Santhakumari AS and Nirmala P. (2014): Nephroprotective effect of silymarin in hyperglycemia-induced oxidative stress in rats. Int J Basic Clin Pharmacol. 3(6): 1030-1035.

[55] Nassuato Rm, Iemmolo M, Strazzabosco F, Lirussi R, Deana Ma, Francesconi MM, Passe D. Effect of Silibinin on biliary lipid composition ... Volume 12, Issue 3, May 1991, Pages 290-295.

[56] Nie Y, Ren D, Lu X, Sun Y, and Yang X. (2015): Differential protective effects of polyphenol extracts from apple peels and fleshes against acute $\mathrm{CCl}_{4}$-induced liver damage in mice. Food Funct. Feb; 6(2):513-24.

[57] Oda SS and El-Ashmawy IM (2012): Protective effect of silymarin on mercury-induced acute nephro-hepatotoxicity in rats. Global Veterinaria 9 (4): 376-383, 2012.ISSN 1992-6197.

[58] OkauT, and Nakamura S. (2014): Evaluation of the relative available energy of several dietary fiber preparation using breath hydrogen evolution in healthy humans. J Nutr Sci Vitaminol, 60:246-254.

[59] Otrubová O, Turecký L, Uličná O, Janega P, Luha J, and Muchová J.(2018): Therapeutic effects of N-acetyl-L-cysteine on liver damage induced by long-term CCl4 administration. Gen Physiol Biophys. Jan; 37(1):23-31.

[60] Ozturk M, Akdogan M;,Keskin I, Kisioglu A.N;,Oztas S and Yildiz K. (2012): Effect of silybum marianum on acute hepatic damage caused by carbon tetrachloride in rats.Biomedical research Volume23, Issue 2

[61] Pacheco GS, Panatto JP (2009): Brain creatine kinase activity is inhibited after hepatic failure induced by carbon tetrachloride or acetaminophen .Metabolic Brain disease 24(3):383-94.

[62] Papackova Z, Heczkova M, Dankova H, Sticova E, Lodererova A, Bartonova L, Poruba M and Cahova M.(2018): Silymarin prevents acetaminophen-induced hepatotoxicity in mice. PLoS One. Jan 17;13 (1):e0191353.

[63] Pereira DI and Gibson GR (2002): Effects of consumption of probiotics and prebiotics on serum lipid levels in humans. Crit Rev Biochem Mol Biol.; 37(4):259-81.

[64] Préstamo G Pedrazuela A, Elena P, Lasunción M A, Arroyo G. (2003):Role of buckwheat diet on rats as prebiotic and healthy food. Nutrition Research Volume 23, Issue 6, Pages 803-814.

[65] Ribeiro WP, Stephanie JV, Pagan JD and Essen B .(2004): The effect of varying dietary starch and fat content on serum creatine kinase activity and substrate availability in equine polysaccharide storage myopathy. Journal of veterinary internal medicine 18(6),887-894.

[66] Rishi P, Kaur Mavi S,Bharrhan S, Shukla G and Tewari R. (2009): Protective efficacy of probiotic alone or in conjunction with a prebiotic in Salmonella-induced liver damage. FEMS Microbiology Ecology, Volume 69, Issue 2, Pages 222-230,

[67] Roberfroid MB. (2007): Prebotics:the concept revisited.J.Nutr;37:830-837.

[68] Sanmugopriya,E and Venkataraman,S (2006): Studies on hepatoprotective and antioxidant actions of Strychnos potatorum Linn.seeds on CCl4 induced acute hepatic injury in experimental rats. J. Ethnopharmacol. 105: 154-160.

[69] Shaarawy SM, Tohamy AA Elgendy SM, Abd Elmageed ZY, Bahnasy A, Mohamed MS, Kandil E. and Matrougui K.(2009): Protective effects of garlic and silymarin on NDEA-induced rats hepatotoxicity. International Journal of Biological Sciences.5 (6):549-557.Ivyspring International Publisher. 
[70] Shahbazi F, Sadighi S, Dashti-Khavidaki S, Shahi F, Mirzania M, Abdollahi A. and Ghahremani MH.(2015): Effect of silymarin administration on cisplatin nephrotoxicity: report from a pilot, randomized, double-blinded, placebo-controlled clinical trial. Phytother Res. Jul; 29(7):1046-53.

[71] Shahwan M, and Zain Al Abdin SM.(2018):Antioxidant, hepatoprotective and lipid lowering activity of Sarcopoterium Spinosum on carbon tetrachloride (CCl4)- induced hepatic damage in rats. J. Pharm. Sci. \& Res. Vol. 10(11), 2800-2804.

[72] Shen B, Chen H, Shen C, Xu P, Li J, Shen, G;Yuan, H and Han, J. (2015): Hepatoprotective effects of lignans extract from Herpetospermum caudigerum against $\mathrm{CCl} 4$-induced acute liver injury in mice. $\mathrm{J}$ Ethnopharmacol, 164: 46 \pm 52 .

[73] Shih CK, Chen SH, Hou WC and Cheng HH (2007): A high resistance starch rice diet reduces glycosylated hemoglobin level and improves the antioxidant status in diabetic rats. Food Research international volume 40, issue 7 pages 842-847.

[74] Siti AZ and Sarbini SR. (2015): The potential of resistant starch as a prebiotic. Critical Reviews in Biotechnology 13(3):1-7.

[75] Shukla A and Bhatia,S.J.(2010):Outcome of patients with primary hepatic venous obstruction treated with anticoagulants alone Indian J Gastroenterol 29(1):14-17

[76] Škottová N, Krečman V, Walterová D, Ulrichová J, Kosina P and Šimánek V (1998): Effect of silymarin on serum cholesterol levels in rats. Acta Univ. Palacki. Olomuc., Fac. Med. Volume 141, 1998

[77] Skottová N, Vecera R, Urbánek K, Vána P, Walterová D, and Cvak L.(2003): Effects of polyphenolic fraction of silymarin on lipoprotein profile in rats fed cholesterol-rich diets. Pharmacol Res. J; 47(1):17-26.

[78] Smazal AL, Borcherding NC Anderegg AS, Schalinske KL, Whitley EM and Rowling MJ (2013): Dietary resistant starch prevents urinary excretion of 25-Hydroxycholecalciferol and vitamin D-binding protein in type 1 diabetic rats. The journal of Nutrition, volume 143, issue 7. Pages $1123-$ 1128.

[79] Sobolova L, Skottova N, Vecera R and Urbanek K (2006): Effect of silymarin and its polyphenolic fraction on cholesterol absorption in rats. Pharmacol.Res., 53(2): 104-112.

[80] Sonnenbichler J, Scalera F, Sonnenbichler I and Weyhenmeyer R. (1999): Stimulating effects of silibinin and silicristin from themilk thistle Silybum marianum on kidney cells. J Pharm Exp Ther, 290: 1375-1383,

[81] SPSS Inc. Released (2009): PASW Statistics for Windows, Version 18.0. Chicago: SPSS Inc.SPSS Inc. Released (2009): PASW Statistics for Windows, Version 18.0. Chicago: SPSS Inc.

[82] Storey D, Lee A, Bornet F and Brouns F. (2007): Gastrointestinal responses following acute and medium term intake of retrograded resistant maltodextrins, classifief as type 3 resistant starch. Eur.J.Clin. Nutr, 61:1262-1270.

[83] Sueyoshi M, Fukunaga M, Mei M, Nakajima A, Tanaka G, Murase T,Narita Y, Hirata S and Kadowaki D.(2019): Effects of lactulose on renal function and gut microbiota in adenine-induced chronic kidney disease rats. Clin Exp Nephrol.; 23(7):908-919.

[84] Taghiabadi E, Imenshahidi M, Abnous K, Mosafa F, Sankian M,Memar B and Karimi G. (2012): Protective effect of silymarin against acroleininduced cardiotoxicity in mice.Evid Based Complement Alternat Med. 2012;2012:352091.

[85] Takeiti CY, Kieckbusch TG and Collares-Queiroz FP. (2010): Morphological and physicochemical characterization of commercial maltodextrins with different degrees of dextrose-equivalent. Int. J.Food Propert.13:411-425.

[86] Takahara E, Ohta S, Hirobe M. (1986) Stimulatory effects of silibinin on the DNA synthesis in partially hepatectomized rate livers. Biochemical Pharmacology 35, 538- 541.

[87] Tayebi Khosroshahi H, Habibzadeh A, Khoshbaten M, Rahbari B, Chaichi P and Badiee AH.(2014): Lactulose for reduction of nitrogen products in patients with chronic kidney disease. Iran J Kidney Dis. Sep; 8(5):377-81.

[88] Turgut F, Bayrak O, Catal F, Bayrak R, Atmaca AF, Koc A, Akbas A, Akcay A and Unal D.(2008): Antioxidant and protective effects of silymarin on ischemia and reperfusion injury in the kidney tissues of rats. Int Urol Nephrol.; 40(2):453-60.

[89] Voroneanu L, Nistor I, Dumea R, Apetrii M and Covic A.(2016): Silymarin in Type 2 Diabetes Mellitus: A Systematic Review and Meta-Analysis of Randomized Controlled Trials. J Diabetes Res.; 2:5147468.

[90] Wu C T, Chiu CY, Huang CF, Peng FC and Liu SH.(2018): Genotoxicity and 28-day oral toxicity studies of a functional food mixture containing maltodextrin, white kidney bean extract, mulberry leaf extract, and niacin-bound chromium complex. Regul Toxicol Pharmacol. ;92:67-74 